\title{
Editor's Introduction: Memorials, Problems and Knowledge
}

\author{
Lawrence T. Nichols ${ }^{1}$
}

Published online: 23 February 2017

(C) Springer Science+Business Media New York 2017

This issue features a rich mixture of papers that can be roughly grouped under the headings of creating knowledge, examining social problems and remembering the contributions of former colleagues that continue to inspire.

We begin with three articles honoring the late Joseph R. Gusfield, a leading proponent of Chicago-style sociology who is best known for his work in the area of social problems and social movements, especially his influential books Symbolic Crusade: Status Politics and the American Temperance Movement and The Culture of Public Problems. Special thanks are due to Peter Conrad, who organized a session commemorating Gusfield at a recent conference of the Society for the Study of Social Problems, which generated the papers presented here. In his introductory paper, Conrad provides a relatively brief but richly detailed biographical sketch. Chandra Mukerji next reminisces about Gusfield at the University of California at San Diego, where he served as founding chair of the department of sociology and helped it become "like living in a family that liked to debate everything." Joel Best then looks at the impact of Gusfield's ideas on the special field of social problems theory, with particular emphasis on the principle of contextual understanding.

We also present three papers by or about George Herbert Mead, who continues to be the subject of much contemporary scholarship, including Daniel Huebner's book, Becoming Mead: The Social Process of Academic Knowledge as well as JeanFrancois Cote's volume, George Herbert Mead's Concept of Society: A Critical Reconstruction, both of which appeared in 2015. In an introductory essay, Cote discusses how Mead became involved with Hawaii via his wife, Helen Castle, whose family owned a plantation near Honolulu. This prepares the way for two papers by Mead, including "Hawaiians Are Fit," which appeared in the Chicago Tribune newspaper in 1898, and "On the Colonization of Hawaii," which Mead delivered as a

Lawrence T. Nichols

lnichol2@wvu.edu

1 West Virginia University, Department of Sociology and Anthropology, 307 Knapp Hall, PO Box 6326, Morgantown, WV 26506, USA 
speech to the National Land Farm Congress in 1909, in Chicago. The latter is taken from the George Herbert Mead Papers in the Special Collections Research Center, Regenstein Library, University of Chicago, and is published here for the first time. Both of Mead's papers may be said to fall into the category of social problems and social policy.

Fran Osrecki's paper connects with this theme, by surveying sociological literature on the problem of political corruption, an issue of much contemporary relevance. She argues that mid-twentieth-century sociological analyses of corruption examined the issue largely from a functionalist perspective that was "counter intuitive." Subsequently, the decline of the functional paradigm was followed by the hegemony of economic models of analysis, to the point where sociology now struggles to make a distinctive contribution to the discourse.

Lonnie Athens, Roberto Cipriano, Sarah Babb, Lara Birk and Luka Carfagna, in various ways, address the question of the creation and transmission of sociological knowledge. Athens offers an historical analysis that focuses on why the approach of Robert E. Park, which he refers to as "radical interactionism," did not become prominent in the field for many decades after its appearance in Park's writings. The answer, he believes, lies in the more successful advocacy for Mead-style interactionism by Herbert Blumer, and in the correspondingly less successful advocacy for Park-style interactionism by Everett C. Hughes. Roberto Cipriano, meanwhile, examines the "surrender and catch" methodology that Kurt Wolff developed, largely under the influence of the phenomenological works of Edmund Husserl and Alfred Schutz. In Cipriano's reading, Wolff's method is an effort to gain scientific knowledge of "the other," and it tends to be a critique of the status quo. Babb, Birk and Carfagna, finally, report on the difficulties of doing qualitative sociology in university contexts where researchers must obtain the approval of Institutional Review Boards (IRBs). Their analysis is based on reports from some two dozen qualitative sociologists at both research universities and liberal arts colleges, who experienced frictions with "a regulatory regime oriented toward the norms of experimental research." Thus, in Athens we learn of "knowledge lost," in Cipriano of "possible knowledge," and in Babb, Birk and Carfagna of "obstacles to knowledge".

Janet Armitage, finally, shares her reflections on Anthony J. Blasi's 2014 book, Sociology of Religion in America: A History of Secular Fascination with Religion. As she details, using self-generated data bases on dissertations and journal articles, Blasi takes readers on "a valuable journey through the evolution of the sociology of religion." Armitage's discussion also indirectly raises the question of the current status of the sociology of religion within the overall field of sociology. My own impression, based on teaching at a dozen colleges and universities, as well as on conversations with colleagues, is that, despite its obvious importance in the social world, religion remains relatively under-studied and under-taught in many academic departments of sociology. In part, this might be due to the anti-religious attitude of the Enlightenment that has remained widespread in sociology from the time of its founding in mid-nineteenth century Europe (though perhaps it is not as prevalent in the United States where sociology also had roots in the Social Gospel movement). In part, this relative neglect might also be due to the pressure that contemporary departments experience to attract majors and to excel in selected areas of curriculum. That is to say, administrators are likely to be more supportive of units that are "strong in criminology" or "strong in 
inequality" than those that are "strong in religion." Undergraduates, meanwhile, might wonder what they would do with their bachelor's degree if their emphasis was in religion, rather than in some more marketable specialty.

And here I wonder whether it is time to broaden this subfield and to rename it as "the sociology of religion and spirituality." As readers doubtless know from experience, many contemporaries describe themselves as "not religious, but a spiritual person." This, I believe, is a significant development that ought to be recognized in our discipline, and I would be very interested in bringing out in this journal articles on "sociology and spirituality." These might draw inspiration from recent work on spirituality in medicine and in business, as well as from the movement toward "positive psychology" associated with Martin Seligman, the late Christopher Peterson and their students and collaborators. According to two famous popular philosophers, the ice cream makers Ben (Cohen) and Jerry (Greenfield), spirituality is really love energy, and we could use much more of that in sociology, in our teaching, research, professional conferences, policy consulting and public service. We need not attempt to create the "religion of humanity" advocated by Auguste Comte, but we would do well to reintroduce the ideal of love (which he celebrated) into both our vocabulary and our professional practice. 